\title{
M.G.Sycheva, T.I.Grushina \\ Pharmacotherapy of radiation-induced pulmonary lesions in oncologic patients
}

Key words: carcinoma, malignant tumours, radiation therapy, radiation-induced lung lesions, pneumonitis, pulmonary fibrosis, rehabilitation, pharmacotherapy, corticosteroids, respiratory mechanics.

Ключевые слова: рак, злокачественные опухоли, лучевая терапия, радиационно-индуцированные повреждения легких, пневмонит, пневмофиброз, реабилитация, фармакотерапия, глюкокортикостероиды, биомеханика дыхания.

Лучевая терапия злокачественных новообразований легких, молочной железы, пищевода, лимфомы Ходжкина с поражением лимфатических узлов средостения приводит к радиационно-индуцированным повреждениям легких (РИПЛ; Radiation Induced Lung Injury - RILI). Новые технологии лучевой терапии понижают повреждающее действие подводимого к опухоли ионизирующего излучения на здоровые органы и ткани, но не исключают его полностью. Именно реакции нормальных тканей являются ограничивающим фактором лучевого лечения многих злокачественных опухолей.

Реабилитация больных с РИПЛ представляет собой серьезную проблему, решение которой позволило бы значительно улучшить качество и продолжительность жизни онкологических больных. Одним из ее методов является лекарственная терапия, используемая как в стационарных, так и в амбулаторных условиях, т. е. на всех этапах реабилитации.

Во врачебном сообществе издавна сложилось мнение [1], что фармакотерапия РИПЛ (лучевого пневмонита и лучевого пневмофиброза) должна включать назначение глюкокортикостероидов (ГКС), антибиактериальных препаратов (АБП), антикоагулянтов прямого и непрямого действия.

ГКС считаются основой лечения лучевого пневмонита. В экспериментальных работах было показано, что назначение ГКС животным во время облучения понизило уровень смертности от лучевого пневмонита, но не повлияло на имеющийся фиброз легкого [2, 3]. По данным [4, 5], ГКС не предотвращали развитие лучевого пневмонита, но давали объективно положительный эффект при применении у больных с его клиническими проявлениями. По мнению авторов исследований [6, 7], ГКС должны назначаться сразу же при выявлении РИПЛ, чтобы избежать развития пневмофиброза.
Лечение лучевого пневмонита обычно начинают с назначения преднизолона в ежедневной дозе 1 мг / кг в течение нескольких недель с дальнейшим постепенным ( $\leq 12$ нед.) ее снижением, т. к. резкая отмена стероидов обостряет симптомы пневмонита [8-11].

На фоне такого лечения клиническое улучшение наступает быстро; впрочем, тяжелые и устоявшиеся случаи могут быть рефрактерны даже к очень высоким дозам ГКС. Изменение рентгенологической картины происходит значительно медленнее. В единичных исследованиях отмечен положительный эффект совместного использования ГКС с иммунодепрессантами (азатиоприном, циклоспорином А) [12], а также с китайской лекарственной терапией (Qingfei Huatan Quyu method) [13].

До настоящего времени крупные рандомизированные клинические исследования, демонстрирующие эффективность ГКС при лечении РИПЛ, отсутствуют.

Что касается применения АБП, то, по мнению ряда авторов [14-17], они малоэффективны в лечении лучевого пневмонита, за исключением случаев присоединения инфекции, к которой больные с РИПЛ предрасположены, а антикоагулянты вообще неэффективны [14-19].

В отечественной литературе существуют единичные исследования, посвященные лечению лучевых пневмонитов.

Л.А.Зориной [20] предложен метод лечения РИПЛ, включающий активную противовоспалительную и терапию АБП, применение отхаркивающих средств и препаратов с противокашлевым и бронхорасширяющим действием. Все больные получали ингаляции с 10-20\%-ным раствором диметилсульфоксида (в ряде случаев дополнительно применялся электрофорез 10\%-ным раствором диметилсульфоксида на грудную клетку над зоной лучевого поражения). Лечение 
дало положительный эффект, оцененный в основном клинически, а также рентгенологическим и рентгенопневмополиграфическим методами. Для получения стабильных результатов лечение рекомендовано повторять 2-3 раза с перерывом 4-6 мес.

В.В.Суравикиной [21] проводилось лечение лучевых пульмонитов с комплексным применением энтеросорбентов (Ваулен), иммуностимулятора (тималин), переливания экстракорпорально облученной аутокрови, солкосерила (актовегина), АБП. Результаты работы оценивались клинически и лишь у части больных были подтверждены рентгенологически констатировалось купирование острых проявлений пульмонита. Терапевтический эффект в 2,2 раза превысил таковой от общепринятых лечебных мероприятий.

И.И.Минайло и соавт. [22] для лечения лучевых пульмонитов использован медикаментозный комплекс из нуклеината натрия, неорондекса, биена, углесорба, что позволило им получить субъективный эффект у $95 \pm 5 \%$, а рентгенологически определяемый положительный объективный эффект - у $91 \pm$ 6 \% больных. Результаты были подтверждены лабораторными показателями - снижением уровня эндогенной интоксикации, уменьшением неспецифической клеточной реактивности крови, повышением эффекторных звеньев иммунитета и функциональной активности транспортных систем крови.

Под наблюдением Л.Ю.Арустамян [23] и Т.И.Грушиной [24] находились больные раком молочной железы с лучевыми повреждениями легких $(n=92)$, 19 из них проводилась фармакотерапия лучевого пневмонита ( $n=10)$ и лучевого пневмофиброза $(n=9)$ : преднизолон (начальная доза 30 мг в течение 5 дней с последующим постепенным понижением), АБП (с учетом чувствительности бактериальной флоры мокроты), бронходилататоры, муколитики (ацетилцистеин), препараты коррекции свертывающей и фибринолитической систем (курантил, трентал), аскорбиновая кислота. Результаты лечения оценивались на основании клинико-рентгенологических данных и исследования биомеханики дыхания (бодиплетизмография). Обследование проводилось до и после лечения. На фоне лекарственной терапии у всех 19 больных отмечалась положительная клиническая динамика: к 8-10-м суткам у подавляющего большинства больных нормализовалась температура тела, уменьшились слабость, одышка и кашель. Одышка продолжала беспокоить 2 больных с лучевым пневмонитом и 4 больных с пневмофиброзом, но уже только при больших физических нагрузках, тогда как до лечения ее вызывали нагрузки малой и средней интенсивности. Частота и интенсивность приступов сухого кашля через 3-5 дней лечения сократилась у 50 \% больных. Жесткое дыхание и сухие рассеянные хрипы продолжали выслушиваться у всех пациентов с лучевым пневмофиброзом и у $50 \%$ больных лучевым пневмонитом.

В результате проведенного 15-дневного курса лечения у больных лучевым пневмонитом достоверно увеличилась на $10 \%$ жизненная емкость легких
(ЖЕЛ) и на $25 \%$ - максимальная объемная скорость выдоха на уровне $75 \%$ форсированной ЖЕЛ (ФЖЕЛ) - МОС $_{75}$, однако отмечено незначительное (в пределах статистической погрешности) снижение показателей ФЖЕЛ и максимальной вентиляции легких. У пациентов с лучевым пневмофиброзом ЖЕЛ увеличилась на $2 \%$; пиковая скорость форсированного выдоха - на $4 \%$, MOC $_{75-25}-$ на $3 \%$ и $2 \%$ соответственно, максимальная вентиляция легких на $1 \%$ (разница в показателях недостоверна). При контрольном рентгенологическом исследовании, проведенном через 3-6 мес. после курса лечения, у 2 больных лучевым пневмонитом рентгенологические признаки лучевого повреждения исчезли, а у 8 сформировался фиброз в виде тяжей или очагов. У всех больных с лучевым пневмофиброзом $(n=9)$ изменения легочной ткани остались прежними.

Л.В.Курсовой и соавт. [25] представлены результаты лечения лучевого пневмонита у 25 больных раком легкого. Больным был назначен комплекс медикаментозных средств, применяемых одновременно или последовательно. В него входили системные и местные муко- и бронхолитики, препараты с кодеином, антагонисты гистаминовых $\mathrm{H}_{1}$-рецепторов, АБП и антимикотические средства с учетом чувствительности флоры, противовоспалительные препараты (в первую очередь кортикостероиды) под прикрытием гастропротекторов, а также нестероидные противовоспалительные препараты, декстраны, пентоксифиллин. Применялись ингаляции 10\%-ного раствора диметилсульфоксида или суспензии гидрокортизона ацетата, флутиказон. При обширном воспалительном процессе, низкой вероятности кровотечения, тромбозе / эмболии в анамнезе назначались гепарин и варфарин под контролем показателей коагулограммы. Также использовались антиоксиданты и цитопротекторы; при необходимости - препараты железа, стероидные и нестероидные анаболики. По показаниям выполнялись плевральные пункции, бронхоскопические санации.

По результатам сложного медикаментозного комплекса, применяемого постоянно в течение 1 года после манифестации пневмонита, в течение 1 года наблюдений из 25 пациентов умерли 5 (от легочного кровотечения -4 , от тромбоэмболии легочной артерии - 1); 5 продолжили противоопухолевое лечение по поводу прогрессирования рака легкого. У 15 пациентов в результате лечения лучевого пневмонита развился пневмофиброз: ІІ степени (по классификации LENT SOMA) - у 7; III степени - у 4, IV степени - у 4. Через 1 год после начала лечения РИПЛ у 15 больных отмечались статистически недостоверные улучшение функциональных показателей внешнего дыхания и показателей самооценки здоровья и индекса Карновского при достоверном увеличении физической активности. При рентгенографическом исследовании легких было выявлено сокращение инфильтративных процессов, уменьшение степени выраженности пневмофиброза до II-III степени. У 2 больных течение лучевого пневмонита осложнилось образованием полостей. 
Под наблюдением В.В.Пасова и соавт. [26] находились больные $(n=50)$ : после лучевой терапии по поводу лимфогранулематоза $(n=19)$, рака легких $(n=18)$ и рака молочной железы $((n=13)$ с лучевыми повреждениями органов грудной клетки, из которых у 9 больных лучевые поражения проявлялись лучевым перикардитом, у 41 - сочетались с РИПЛ. При лечении больных лучевыми пневмонитами и пневмофиброзами также использовался аналогичный комплекс медикаментозных средств. В результате у больных пневмонитами наблюдался регресс воспалительных изменений легочной ткани, у 18 \% полное восстановление структуры и функции легких.

Л.В.Курсовой и соавт. [27] проведено лечение больных раком легкого с РИПЛ $(n=12)$, осложненными хроническим гнойно-деструктивным процессом. Применяемый комплекс медикаментозных средств был дополнен парахирургическими манипуляциями - чрескожным трансторакальным введением антисептиков и бактериофагов, а также бронхоскопическими санациями. Использованная методика лечения не позволила ликвидировать полость эмпиемы или абсцесса, но привела к улучшению клинической и рентгенологической картины и сокращению числа обострений. Для всех пациентов в результате лечения удалось достичь индекса функциональной активности Карновского 60-80 \% (в среднем $70 \%$ ). Из 12 больных, наблюдаемых в течение 2-5 лет, 3 прожили после образования полости от 2 до 3 лет и скончались от аррозионного легочного кровотечения, 9 - живы.

Сделан вывод о необходимости поэтапного применения данного комплекса медикаментозных средств и предупреждения деструкции легочной ткани путем своевременного лечения лучевых пневмонитов с применением прежде всего ГКС в адекватных дозах и на достаточно длительный срок.

Фармакотерапия лучевых пневмофиброзов не имеет особой специфичности [28] и включает санацию бронхиального дерева (АБП с учетом чувствительности флоры мокроты), восстановление дренажной функции бронхов (бронхолитики и отхаркивающие средства), улучшение микроциркуляции в пораженных тканях (дезагреганты, антикоагулянты, сосудорасширяющие препараты) и применение диметилсульфоксида, обладающего противовоспалительным, коллагенизирующим и антиэкссудативным свойствами $[26,29,30]$. Вопрос о назначении ГКС решается индивидуально, т. к. они малоэффективны в лечении поздних лучевых пневмофиброзов. Также таким пациентам показана кислородотерапия [10].

В последние годы появились работы по изучению действия системной трансплантации аутологичных мезенхимальных стволовых клеток на РИПЛ как в самостоятельном режиме, так и в сочетании со ставшим традиционным комплексом медикаментозной терапии. Предварительными экспериментальными данными показано, что трансплантация клеток уменьшает смертность животных от РИПЛ.

Клиническими исследованиями $(n=11)$ показано, что проведение клеточной терапии не привело к значительным изменениям показателей спирограммы, иммунограммы и сцинтиграммы легких, маркеров воспаления и тканевой гипоксии у больных, что было расценено как стабилизация процесса [31, 32].

\section{Заключение}

Научные работы по фармакотерапии РИПЛ крайне немногочисленны. Как по числу и контингенту наблюдаемых больных, так и по методологии исследования эти работы могут быть охарактеризованы как пилотные исследования. Методы фармакотерапии подбираются эмпирически и лечение лучевых повреждений легких, по своей сути, является симптоматическим. Анализ полученных результатов лечения больных показал, что на настоящий момент возможности медикаментозного лечения РИПЛ весьма ограничены.

В связи с этим подавляющим большинством исследователей, с одной стороны, осуществляется поиск медикаментозных способов профилактики, предупреждения и минимизации РИПЛ, с другой разрабатываются новые методы лучевой терапии онкологических больных.

Все исследования в области профилактики и лечения РИПЛ должны проходить параллельно. Окончательные выводы о неэффективности фармакотерапии РИПЛ преждевременны, т. к. отсутствуют серьезные рандомизированные исследования и разработки по оценке отдельных методов, способствующих повышению их результативности, на масштабном клиническом материале с длительными сроками наблюдения больных.

\section{Литература}

1. Moss W.T., Haddy F.J., Sweany S.K. Some factors altering the severity of acute radiation pneumonitis: variation with cortisone, heparin and antibiotics. Radiology 1960; 75: 50-53.

2. Gross N.J., Narine K.R., Wade R. Protective effect of corticosteroids on radiation pneumonitis. Radiat. Res. 1988; 113: 112-116.

3. Ward H.E., Kemsley L., Davies L. The effect of steroids on radiation-induced lung disease in the rat. Radiat. Res. 1993; 136: 22-25.

4. Rubin P., Johnston C.J., Williams J.P. A perpetual cascade of cytokines postirradiation leads to pulmonary fibrosis. Radiat. Oncol. Biol. Phys. 1995; 33: 99-101.

5. Rubin P., Casarett G.W. Clinical radiation pathology. Philadelphia; 1968. 79-88.

6. Rodriguez M.L., Padellano L.C. Toxicity associated to radiotherapy treatment in lung cancer patients. Clin. Transl. Oncol. 2007; 9 (8): 506-512.

7. Yanf M.H., Dou Y.Q., Zang Q. Effects of blood-cooling and promoting drugs on rats with radiation-induced lung injury. Zhongguo Zhong Xi Yi Jie He Za Zhi 2007; 27 (9): 827-831.

8. O'Donnell P.H. Radiation pneumonitis. In: Hall J.B., Schmidt G.A., Hogarth D.K. Critical care medicine. Just the facts. New York: McGraw-Hill companies; 2007. 278-280.

9. Михина 3.П. Лучевая терапия при раке легкого. В кн.: Новое в терапии рака легкого. М.; 2003. 144-146. 
10. Movsas B., Raffin T.A., Epstein A.H., Link Jr C.J. Pulmonary radiation injury. Chest 1997; 111 (4): 1061-1076.

11. Berkey F.J. Managing the adverse effects of radiation therapy. Am. Fam. Physician. 2010; 82 (4): 381-388, 394.

12. Diaz M.G., Condomines J.R. Radiation pneumonitis. In: E.Azoulay, ed. Pulmonary involvement in patients with hematological malignancies. Berlin; Heidelberg: SpringerVerlag; 2011. 499-507. DOI: 10.1007/978-3-642-157424_38.

13. Lin S.Y., Han X.H., Yang Q.C. Treatment of acute radiation pneumonia with Qingfei Huatan Quyu method. Zhongguo Zhong Xi Yi Jie He Za Zhi 2008; 28 (5): 414-417.

14. Rubin P., Casarett G.W. Clinical radiation pathology. Philadelphia: WB Saunders; 1968. 423-470.

15. Gross N.J. Pulmonary effects of radiation therapy. Ann. Intern. Med 1977; 86: 81-92.

16. Rubin P., McDonald S., Maasilta P. Serum markers for prediction of pulmonary radiation syndromes. Radiat. Oncol. Biol. Phys. 1989; 17: 553-554.

17. Rotstein S., Blomgren H., Baral E. et al. Incidence of infectious symptoms after radiation therapy for breast cancer: long-term effects. Acta Oncol. 1987; 26 (3): 197-201.

18. Kimsey F.C., Mendenhall N.P., Ewald L.M. Is radiation treatment volume a predictor for acute or late effect on pulmonary function? A prospective study of patients treated with breast-conserving surgery and postoperative irradiation. Cancer 1994; 73: 2549-2551.

19. Птушкин В.В. Лечение и профилактика осложнений химиолучевой терапии у больных с лимфомами. Практ. онкол. 2004; 5 (3): 223-230.

20. Зорина Л.А. Поздние лучевые повреждения легких после лечения рака молочной железы: Автореф. дис. ... канд. мед. наук. Обнинск; 1988.

21. Суравикина В.В. Профилактика и лечение постлучевых пульмонитов при интенсивной лучевой и химиолучевой терапии у неоперируемых больных раком легкого: Автореф. дис. ... канд. мед. наук. Минск; 1996.

22. Минайло И.И., Артемова Н.А., Смолякова Р.М., Невская Л.Л. Постлучевые (посттерапевтические) пульмониты: новые подходы к комплексному лечению. Вестник фонда фундаментальных исследований (Минск) 2006; 1 (35): 59-69.

23. Арустамян Л.Ю. Лечение лучевых повреждений легких у больных раком молочной железы с использованием искусственного магнитного поля: Автореф. дис. ... канд. мед. наук. М.; 2002.

24. Грушина Т.И. Реабилитация в онкологии: физиотерапия. М.: ГЭОТАР; 2006.

25. Курсова Л.В., Иванова И.Н., Мардынский Ю.С. и др. Лучевые пневмониты у больных раком легкого. Сиб. онкол. журн. 2010; 38 (2): 51-54.

26. Пасов В.В., Зубова Н.Д., Иволгин Е.М., Курпешева А.К. Поздние лучевые повреждения грудной клетки. Сиб. онкол. журн. 2009; 36 (6): 58-61.

27. Курсова Л.В., Рагулин Ю.Л., Золотков А.Г., Мардынский Ю.С. Консервативное лечение лучевых повреждений легких, осложненных абсцедированием. Сиб. онкол. журн. 2012; 51 (3): 60-66.

28. Westbury C.B., Yarnold J.R. Radiation fibrosis - current clinical and therapeutic perspectives. Clin. Oncol. (Roy. Coll. Radiol.) 2012; 24 (10): 657-672.

29. Бардычев М.С. Лечение местных лучевых повреждений. Лечащий врач: 2003; 5: 78-79.

30. Цыб А.Ф., Бардычев М.С. Лучевая терапия и лучевые повреждения. В кн.: Научно-технический прогресс отечественной лучевой диагностики лучевой терапии: Материалы конференции, посвящ. 80-летию РНЦРР. М.: ВЕЧЕ; 2004. 288-289.

31. Курсова Л.В., Коноплянников А.Г., Пасов В.В. и др. Возможности применения аутологичных мезенхимальных стволовых клеток при лечении лучевых повреждений легких. Клеточ. технол. в биол. и мед. 2009; 2: 108-112.

32. Li X., Хue J., Lu Y. Current situation and prospect of treatment for radiation-induced lung injury. Sheng $\mathrm{Wu} Y i \mathrm{Xue}$ Gong Cheng Xue Za Zhi 2010; 27 (4): 937-940.

\section{Информация об авторах}

Сычева Марина Генриховна - к. М. н., ст. научный сотрудник отдела реабилитации больных с заболеваниями бронхолегочной системы ГБУ "Московский научно-практический центр медицинской реабилитации, " "Московский научй и спортивной медицины" Департамента здравоохранения Москвы; тел.: (916) 974-68-63; e-mail: sytchevameister @gmail.com

Грушина Татьяна Ивановна - д. м. н., руководитель отдела медицинской реабилитации онкологических больных, ГБУ "Московский научнопрактический центр медицинской реабилитации, восстановительной и спортивной медицины" Департамента здравоохранения Москвы; тел.: (916) 774-19-39; e-mail: tgrushina@gmail.com

Поступила 05.09.13 (с Сычева М.Г., Грушина Т.И., 2013 удк [616.24-001.29-02:617.54-006]-085.27 